\title{
The ceramic trail: Evaluating the Marianas and Lapita West Pacific connection
}

\author{
Geoffrey R. Clark and Olaf Winter
}

\begin{abstract}
Establishing the prehistoric migration pattern from the similarity of pottery attributes is a fundamental archaeological approach that was validated in the Pacific by the recognition that Lapita ceramics dated to c. 3200-2650 years ago are distributed from south New Guinea to Samoa. Recent work has suggested a connection between Lapita ceramics and the oldest pottery from the Mariana Islands based on the similarity of selected traits that are also widespread in Neolithic and Iron Age assemblages of the region. We compared decoration, vessel form and tool type in Lapita Western Pacific and early Marianas pottery assemblages to determine whether a Marianas ceramic signal can be detected in Lapita pottery from the Bismarck Archipelago. Results indicate that Marianas ceramics are significantly different from Lapita pottery and the presence of simple ceramic traits in different assemblages do not of themselves provide evidence for a migration from the Marianas to the Bismarck Archipelago.
\end{abstract}

\section{Introduction}

The Neolithic expansion of people in Island Southeast Asia (ISEA) and the Western Pacific is demonstrated by the long-distance movement of obsidian and the appearance of sites containing pottery c. 4000-3000 years ago (Bellwood 2011; Bellwood and Koon 1989; Reepmeyer et al. 2011). A central tenet of Indo-Pacific prehistory is a straightforward assumption that maritime dispersals - whether by migrating farmers or not—in this vast area can be tracked from the similarity of material culture assemblages (Solheim 1964a). The utility of this approach in relation to ceramics was exemplified by Golson's (1972:176) early recognition that 'variants of the same pottery tradition', which became known as the Lapita Cultural Complex, could be traced from New Britain in the west to Tonga and Samoa in the east. Subsequent research has only strengthened the view that Lapita culture represents a relatively rapid and extensive Neolithic migration (Denham et al. 2012), yet the successful identification of Lapita ceramics also generated an expectation that other pottery traditions (cord-, basket-, paddle-impressed, incised, appliqué) might represent major dispersal events. This expectation has not been fully realised in ISEA beyond the identification of pottery styles representing possible ancestral wares and derived traditions (e.g. Nusantao-Sa-huynh-Kalanay, Bau-Malay, Novaliches, Dapenkeng red-slipped wares) (Bellwood 1978, 2011; Solheim 1964b, 2000). 
The origins and historical relationships of these early Indo-Pacific pottery assemblages are controversial and here we compare early pottery from the Marianas Islands in Western Micronesia with Lapita ceramics from the Western Pacific. The Mariana Islands were the first Remote Oceanic island group in the Pacific Ocean to be colonised in the Neolithic, despite being more than $2000 \mathrm{~km}$ from ISEA-New Guinea, and the migration source is currently unresolved (Fitzpatrick and Callaghan 2013; Hung et al. 2011; Winter et al. 2012). Human arrival in the Marianas at $3500 \mathrm{cal}$. BP is generally accepted, although some work proposes colonisation at 3300-3200 cal. BP (Clark 2004; Petchey et al. 2017), similar to the age of Lapita arrival in the Bismarck Archipelago (Sheppard et al. 2015). The oldest ceramics from the Marianas have recently been compared with pottery from the Northern Philippines and Western Pacific Lapita culture with two significant migrations proposed (Figure 2.1). The first, from the northerncentral Philippines is thought to have brought red-slipped and dentate/circle-stamped and lime-infilled pottery to the Marianas, while the second and more speculative migration involved a movement from the Marianas to the Bismarck Archipelago (Carson 2014; Carson et al. 2013; Hung et al. 2011). The arrival of potters from the Marianas in Island Melanesia introduced 'some of the Lapita decorative repertoire into Oceania' (Bellwood 2011:S369).

There has been no formal ceramic comparison of early Marianas pottery with Lapita assemblages to evaluate inter-archipelago relationships and the possibility that the synthesis of different Neolithic groups gave rise to the dynamic migratory culture of Lapita. We begin this task by comparing early designs and vessel forms from the Marianas with those of Western Pacific Lapita assemblages to identify shared stylistic and morphological attributes.

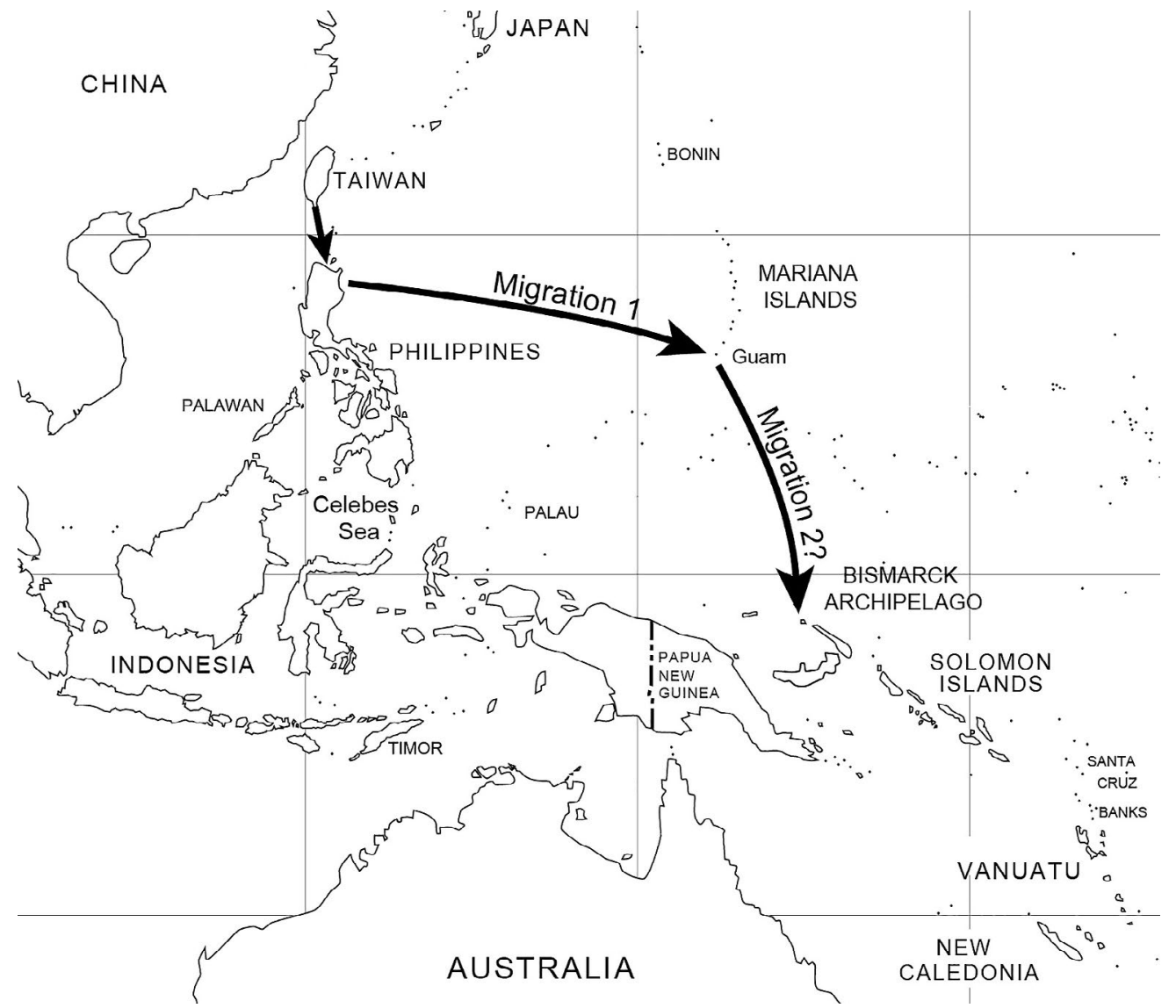

Figure 2.1. Map showing presumed Neolithic migrations from: 1) the Northern Philippines to the Marianas, and 2) the Marianas to the Bismarck Archipelago.

Source: Authors' depiction, after Bellwood 2011: Figure 1 and Carson et al. 2013: Figure 1. 


\section{Methods}

\section{Design comparison}

Pottery comparisons in ISEA and the Pacific have typically involved an informal or formal assessment of ceramic attributes in prehistoric and ethnographic assemblages, with decoration viewed as the most powerful indicator of prehistoric interaction/migration, followed by similarity in vessel form and production technique (e.g. Gifford 1951; MacLachlan 1938; Solheim 1952, 1964a, 1964b). The oldest ceramics in the Marianas were described as 'Marianas red wares/ redwares' due to the presence of a red slip (Marck 1977:36; Spoehr 1957:117-118), with lime infilling and punctate- and circle-stamped pottery recorded by Spoehr (1957) and Pellett and Spoehr (1961). An important distinction was made by Butler, who identified two types of early decoration in the Marianas. Achugao Incised was characterised by:

complex, predominantly rectilinear incised patterns with the zones between the major elements packed with tiny, delicate punctations. Curvilinear incision was present and stamped circles accompanied both rectilinear and curvilinear bands. Lines of punctate stamping were made (vertical, horizontal, diagonal) relative to the vessel axis along chevrons (Butler 1994:27).

San Roque Incised consisted of:

bands of curvilinear garlands made by linking incised arches (half circles) with small stamped circles or large punctations placed at the junctions of the arch segments ... Also rows of stamped circles appear sometimes with this style (Butler 1994:27).

The two early types of decoration simplified over time with bold incised lines, circle/punctate stamping, single-tool punctation and lime infill decoration (Craib 1990; Moore and HunterAnderson 1999). The frequency of Achugao and San Roque decorated pottery is always low within the total percentage of decorated pottery, under 2 per cent in early sites, and the reconstruction of pottery designs is complicated by small sherd size, low image resolution and incomplete assemblage documentation as a result of large-scale archaeological investigations associated with development projects.

To generate a first set of ceramic designs from early sites in the Marianas, we used published sources (line drawings and photographs) of decorated ceramics from seven sites along with sherds from the Bapot-1 site excavated by the authors in 2008 (Winter 2015). The sites are: Achugao, Bapot-1, San Roque, Chalan Piao (Saipan), Unai Chulu, Taga (Tinian), and Mangilao (Guam). Sherds from the Achugao site have been published repeatedly (e.g. Bellwood 2005: Figure 7.3; Hung et al. 2011: Figure 3; Moore and Hunter-Anderson 1999: Figure 3; Rainbird 2004: Figure 4.2) and the number of unique decorated sherds in the literature is surprisingly small. Sherd photographs were digitised, and the images processed (e.g. Bicubic smoother, Lab colour, Invert, Smart sharpen) with Adobe Photoshop to improve image resolution and to identify designs and tool markings. Line drawings and enhanced images of sherds were scanned and drawn in Adobe Illustrator.

The principal sherds are shown in Appendix 2.1 and are identified to a site and publication. Sherds that were too small to allow identification of a design/motif or that had similar designs to those on selected sherds were not included. The second step in extracting a design involved the repetition of whole or partial designs and flattening of the design to remove the effects of vessel curvature (Appendix 2.2). Achugao Incised designs, in particular, were often incomplete and could be extrapolated to make a variety of simple and complicated designs using transformations commonly employed by potters (reflection, rotation, translation-duplication). The final transformation applied to several designs was to simplify/modify designs to create a number of potential variants. For example, a rim-body sherd from Achugao has a design composed of 
an incised rectangle enclosing diagonal punctate stamping (Appendix 2.2:40). The rectangle was surrounded by a second incised rectangle and outlined by stamped circles. Finally, a row of diagonal punctate stamping was placed beneath a line of stamped circles. Removing design elements results in a series of simplified designs ending in a single incised rectangle enclosing diagonal punctate (see Appendix 2.2:38). The majority of Achugao and San Roque designs are simple with designs repeated (translation) to make rows/bands around the circumference of a vessel. The exceptions are several 'interlocking' forms that represent speculative reconstructions made from incomplete Achugao Incised sherds that hint at the existence of a formal design system with significant complexity (Appendix 2.2:65-74). There is also tantalising, but inconclusive, evidence for complex designs that were used as panels/gap fillers between design bands, as seen on some Lapita vessels (e.g. Sand 2015: Figure 4). The description of complex designs is important for identifying the origins of the people who colonised the Marianas and for examining interaction among early Neolithic groups, and the validity of 'interlocking' and 'panel' designs needs to be verified in future study.

\section{Vessel comparison}

In the Marianas only 12 early ceramic sites have been identified (Carson 2014) compared to more than 220 Lapita sites (Bedford and Sand 2007; now 293, see Chapter 1). Complete/ partially complete pots have been recovered from Lapita sites in Fiji, New Caledonia and Vanuatu (Bedford et al. 2010; Birks 1973; Sand 2010), but no complete early vessels have been recovered from the Marianas. Estimates of vessel size and shape from sherd fragments are difficult, and reconstructed vessel forms likely vary among researchers, including ourselves. For example, a carinated jar with a vertical high neck that is very similar to Lapita carinated vessels was initially recorded at Bapot-1 (Carson 2008: Figure 5), but an in-depth study of a larger ceramic assemblage did not identify this vessel (Winter 2015). As Sand (2015:125) notes, insufficient information about Lapita vessels prevents a 'comprehensive study of the differences in pottery typology between sites'.

For the Marianas, we used rim profiles in published and unpublished reports to reconstruct vessel forms from five sites (Bapot-1 (2005), Unai Chulu, Tarague, Mangilao and Taga) and used a simple rim measurement tool on the large Bapot-1 sherd assemblage excavated in 2008. The tool consisted of a vertical and a horizontal ruler mounted on a board with a light source used to illuminate the rim angle. When the correct rim angle is found, measurements are taken and plotted on graph paper to establish the vessel profile. Rim diameters of small sherds were extrapolated by scanning and replicating the curved section to estimate orifice size. Experimental tests with broken sherds from vessels with a known diameter showed these methods to be more accurate than the standard vessel reconstruction methods (e.g. Rice 1987:222-223).

Only Lapita vessels with a clearly defined Far Western - Early Lapita component were examined, as contact between the Marianas and Lapita groups is thought to have taken place early in the Lapita Western Pacific dispersal (Bellwood 2011). Selected vessels and rim forms were available for four sites in the Bismarck Archipelago (Talepakemalai, Adwe, Kamgot and Tamuarawai) (Kirch et al. 2015; Sand 2015) and were scanned and redrawn to the same scale. 


\section{Results}

\section{Design comparison}

The exercise resulted in a list of 74 Marianas designs, which were divided into four groups. Group 1 is the largest ( $\mathrm{n}=27$, Appendix 2.2:1-27) and mostly includes those described as San Roque Incised by Butler (1994, 1995), with incised or stamped circles associated with undulating incised lines arranged in shallow or deep arcs, often joined together but also arranged separately. Linear and sub-linear incised/punctate-stamped designs in an upside-down ' $\mathrm{V}$ ' shape surmounted by a circle are also in this group. The designs extracted from published sherds likely underestimate by a significant margin the amount of design variation. Group 2 ( $n=20$, Appendix 2.2:27-47) is rectilinear except for three examples containing curvilinear arcs, and there is a strong tendency for linear incised spaces to be infilled with punctate stamping (vertical, diagonal, chevron). This group contains sherds described previously as Achugao Incised that can be accompanied by stamped circles and linear incision. The main design forms are incised rectangles and a square/ rectangular wave pattern usually composed of an inner and an outer incised line with the inner rectilinear space(s) infilled with vertical or diagonal punctate. The square/rectangular wave can be accompanied by rows of circles and punctate stamping. Group 3 ( $n=17$, Appendix 2.2:48-64) contains incised/stamped circles/part-circles accompanied by multiple-/single-punctate stamping and incision. These designs are often located on the vessel neck and may have been used as borders for designs in Groups 1 and 2. It is notable that Group 1 designs are seldom associated with punctate stamping while the rectilinear designs of Group 2 are not associated with the circle and arc-forms prominent in Group 1, suggesting separation of the design systems as noted by Butler (1995). Group 4 ( $n=10$, Appendix 2.2:65-74) includes several extrapolations with four examples of the rectangular meander designs (also known as 'J' or 'hook' pattern), two examples of a possible ' $\mathrm{Y}$ ' design and one ' $\mathrm{Z}$ ' design. Diagonal stepped and enclosed stepped rectilinear forms comprise the remainder (Appendix 2.2:72-74).

We compared the early Marianas pottery designs to those in the Lapita Pottery Online Database (lapita.rchss.sinica.edu.tw/web/), and the motif lists of Anson (1983) and Hedrick (n.d.) in addition to published designs (e.g. Bedford et al. 2010; Chiu 2015; Kirch et al. 2015; Noury and Galipaud 2011; Sand 2015; Summerhayes 2000a). A significant difference is the frequent use of dentate lines/arcs in Lapita ceramics as opposed to plain stamp/incision in the Marianas. Designs were considered similar based on the overall pattern, and it was not required that designs be made with the same type of tool (see below). Similarly, if the main part of a design was found in both assemblages, or a Marianas design could be matched with a Lapita design by making a simple transformation, it was also counted. The decision to count designs as similar even if they were made with a different tool and required transformation(s) should maximise interassemblage similarity. For example, the presence of overlapping stamped/incised circles in the Marianas was counted as having a Lapita dentate analogue even though dentate-stamped/incised circles were not accompanied by rows of single-tool punctate, and the inclusion of vertical rows of punctate stamping required the removal of stamped circles from the Marianas design to match the Lapita motif. 


\section{Marianas Transformation Lapita}

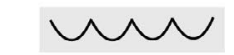

incised $\rightarrow$ dentate

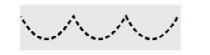

2<smiles>CCCCCCCCCCCC</smiles>

incised $\rightarrow$ dentate

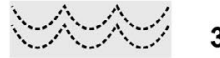

5 riri

incised $\rightarrow$ dentate, reflection

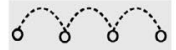

389

10<smiles>CC(=O)CC(C)OC(=O)CC(C)(O)CO</smiles>

incised $\rightarrow$ dentate, reflection, remove stamped circles

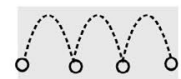

196

$14 \quad$ OOOOOOO

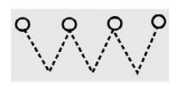

20

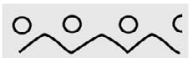

incised $\rightarrow$ dentate

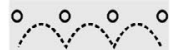

25<smiles>CCCCC(CCC)(CCC)CCCO</smiles>

incised $\rightarrow$ dentate, remove stamped circles

incised $\rightarrow$ dentate, add linear dentate

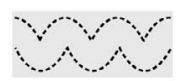

53
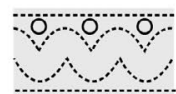

62
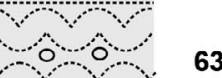

63

64
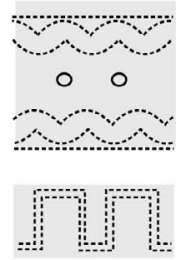

250

498

421

448

435

416

417

274

Figure 2.2. Comparison of Marianas pottery designs with Lapita motifs identified by Anson (1983). Marianas design 29 has not been identified and represents a simplified design derived from those shown in Appendix 2.2:29-36. There are few direct equivalents and most Marianas designs require one or more transformations to match a Lapita motif. Source: Authors' depiction, after Anson 1983. 
A total of 16 Marianas designs/partial designs could be identified in West Pacific Lapita assemblages, but if punctate stamping was a criterion for inclusion then the number would decrease to four. In addition, several of the Marianas designs compared to Lapita sherds by Carson et al. (2013) are unlikely to represent truly similar designs. Rows of stamped circles separated by incised lines on a sherd from Taga in Saipan were compared to designs in the Bismarck Archipelago (2013: Figures 7.4 and 7.5). The Lapita design is different in the use of incision/ dentate to enclose several stamped circles and the likelihood that circles were aligned vertically on Lapita vessels rather than horizontally as in the Marianas (see Anson (1983) motifs 102-105, 114, 119). Another example is Bellwood's (2011: Figure 3) design sequence featuring a Marianas punctate- and circle-stamped rectilinear design (Appendix 2.2:40) found at Achugao, which is hypothesised to transform to a complex Lapita design after contact/migration. The Lapita design is recorded from New Caledonia (see Hung et al. 2011: Figure 4:3) and a recent reconstruction of it by Noury and Galipaud (2011: Figure 5) suggests the design was part of a face-headdress image that is a fully developed and complicated design found in the oldest Lapita assemblages (like those from Mussau) that does not occur in the Marianas. Extracting and comparing design fragments from large and complex designs is unlikely to reveal the historical connections between groups in prehistory. Although the percentage of potentially shared Marianas designs is high — c. 22 per cent (16/74) — this is mainly due to the inclusive criteria used to score similarity.

A more accurate approach is to examine the frequency of Marianas designs in the decorationrich Lapita assemblages. The Anson (1983) Lapita motif list contains 516 designs and there are 16 Marianas designs that overlap in some way with 18 Anson motifs, giving a similarity value of 3.5 per cent (Figure 2.2). The most complex shared design is an undulating pattern (Appendix 2.2:25-26), with most designs simple and consisting of stamped circles, linear and chevron punctate/dentate. The majority of Marianas designs require one or more transformations to be considered similar to a Lapita motif. None of the more complicated rectilinear or curvilinear designs in the Marianas appear in Lapita assemblages such as the square wave with punctate-stamp infilling (Appendix 2.2:31-37). In Lapita ceramics the square/rectangular wave is often associated with 'face' or 'house' designs (Anson 1983; Sand 2015) that are not found in the Marianas. Another important difference in the two decorative systems is their different interlocking designs. In the Marianas, a sherd from Taga may show a rectangular meander (Appendix 2.1:3, see possible variants in Appendix 2.2:65-68, the design may also be a variant of the square wave) similar to the classic meander pattern found in many parts of the world, including Mainland and Island Southeast Asia. (e.g. Bellwood 1978: Figures 7.18, 8.10, 8.11, 8.14; Solheim 1959). The Lapita labyrinth design is a more complicated version of the meander (see Figure 2.3) and is usually placed at an angle similar to how the design is used in textiles (e.g. Buckley 2012).

We have distinguished between designs made with punctate-stamped tools (Marianas) and dentate-stamped tools (Lapita West Pacific) because some Achugao Incised sherds appear to have been made with a different type of multi-toothed tool than that used by Lapita potters. In Figure 2.4, a sherd of Achugao Incised from the Bapot-1 site (Unit 4:240-250 cm depth) on Saipan is shown next to a Lapita sherd from the Malekolon (EAQ) site (Ambitle Island, Bismarck Archipelago). The toothed tool in the Marianas has teeth that have a rounded cross-section, pointed end and a relatively long 'bridge' between each tooth compared with Lapita dentate stamps that have sub-rounded edges, square-to-rectangular teeth and a narrow bridge between teeth. There is significant variation in the punctate tools used in the Marianas, but the probable round and pointed tool used to mark early Achugao Incised pots at Bapot-1 (and possibly other sites like Achugao and Unai Chulu) has not been clearly identified in Neolithic assemblages that we have seen, including Nagsabaran (Northern Philippines) (Hung 2008), multiple Lapita assemblages (Bismarcks, Vanuatu, Fiji, Tonga), and decorated dentate- and circle-stamped pottery from northern Sulawesi (Azis et al. 2018). 


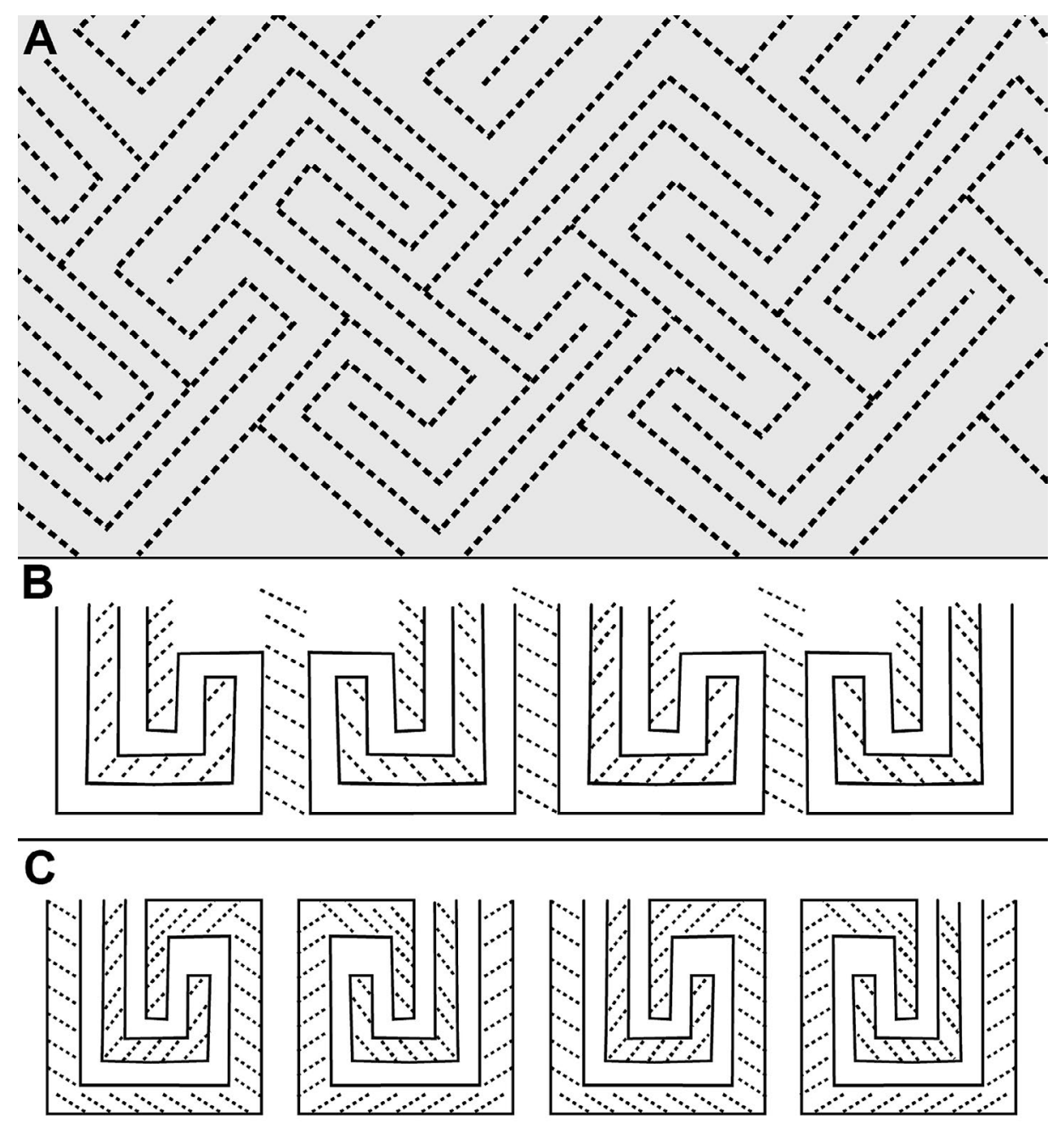

Figure 2.3. (A) Labyrinth design found in West Pacific Lapita assemblages (see variants in Chiu 2015: Table 6). (B) and (C) Possible rectangular meander design from the Marianas. Source: Authors' depiction.

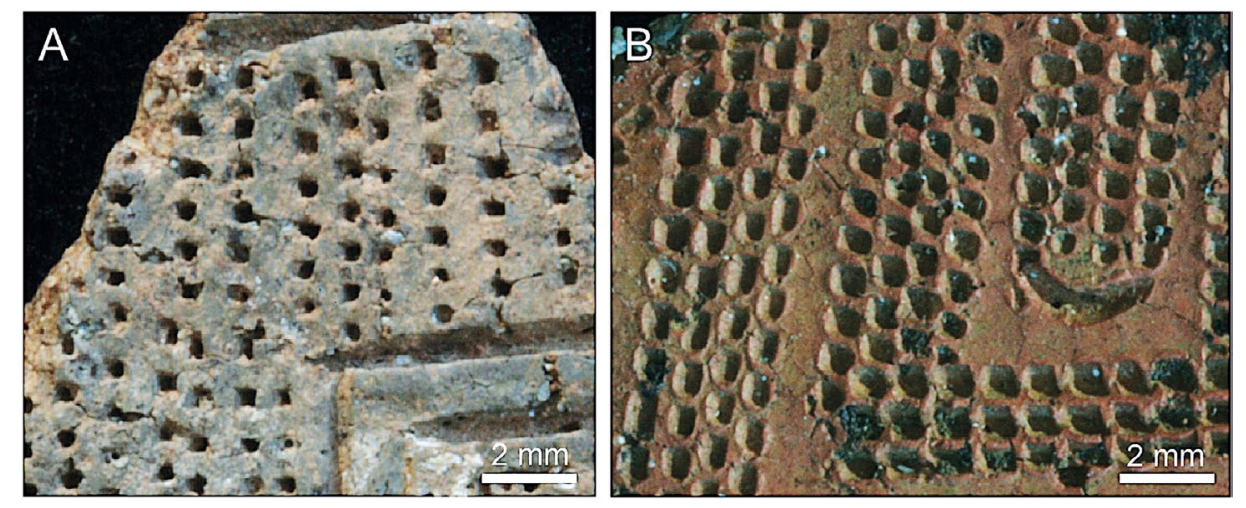

Figure 2.4. (A) Punctate tool-stamped Achugao sherd from the Bapot-1 site (Saipan) in the Marianas dated to 3200-3080 cal. BP (Petchey et al. 2017). (B) Dentate-stamped sherd from the Malekolon (EAQ) site (Ambitle Island, Bismarck Archipelago).

Note the difference in impressions, which indicates that different tool types were used to mark ceramics in the Marianas compared with those used by Lapita potters.

Source: Authors' photos. 


\section{Vessel comparison}

Marianas (Figure 2.5): In the Marianas there are relatively few early vessel forms and these exhibit a range of simple forms. Early 'red ware' vessels are predominantly jars or bowls. Below the neck, the jars are often globular/sub-globular although carinations are relatively common. At Bapot-1, the most common early vessel is a simple jar with an everted rim that comprises 90 per cent of the total assemblage (Winter 2015: Appendix 1:87). Other vessel forms include restricted and unrestricted bowls and dishes. A possible pedestal stand is reported from Bapot-1 by Carson (2014:67) (see Figure 2.5: Bapot-1 B), but it was initially identified as a lid fragment (Carson and Welch 2005:31) and its status is uncertain. At Chalan Piao, Moore et al. (1992:39) report a sherd from a vessel or vessel stand with a cut-out. Early Marianas vessels are generally small, with orifice diameters varying from 10 to $35 \mathrm{~cm}$ (mean $20 \mathrm{~cm}$ ) at Bapot-1 (Winter 2015), and at Taga from 8 to $28 \mathrm{~cm}$ (Carson 2014:127 notes that most vessels have diameters in the $10-20 \mathrm{~cm}$ range) These vessel dimensions are consistent with those recorded in previous studies of Marianas pottery (Butler 1995; Hunter-Anderson and Butler 1995; Moore 1983). Carson (2014:126-127) has noted a correlation between size and vessel decoration at Taga. Bowls decorated with circles along the rim or lip were the largest vessels (diameter 20-28 cm) followed by paddle-impressed vessels (diameter $20-25 \mathrm{~cm}$ ). Vessels decorated with overlapping circle motifs tended to be the smallest bowls (diameter $8-15 \mathrm{~cm}$ ) and vessels decorated with 'Achugao Incised' motifs were small carinated bowls (diameter 10-15 cm) (Carson 2014:126-127).

Lapita Western Pacific (Figure 2.6): The Talepakemalai (ECA) site (Eloaua Island, Mussau Islands) is dated to $3350 \mathrm{cal}$. BP and contains 12 different pottery forms (bowl, bowl on ringfoot, dish, dish on ringfoot, ringfoot, cylinder stand, ring stand (drum), jar, narrow-necked jar, pot, lid and handle), but four dominate: bowls $(n=76)$, dishes $(n=95)$, ringfeet $(n=204)$ and jars $(n=71)$, which account for 86 per cent of the total assemblage $(n=517)$. The orifice diameter for the bowls and jars in Figure 2.5 is c. $20-45 \mathrm{~cm}$, while the diameters for several stand bases is similar at $25-45 \mathrm{~cm}$ (Kirch et al. 2015). Adwe is located in the Arawe Islands, just south of New Britain and the FOH site is dated to 3350-2900 cal. BP. Summerhayes (2000a, 2000b, 2001) identified three ceramic categories comprising eight vessel forms (Category A, Forms I-III unrestricted vessels; Category B, Forms IV-VII restricted vessels; Category C, Form VIII, vessel stands). The most common vessel at FOH is Form V (jar with outcurving rim, restricted neck and carination), which made up 60 per cent of the assemblage. The orifice diameters of the bowls and jars presented varies from 34 to $40 \mathrm{~cm}$. In the FOH squares D/E/F and FNY, 3-8.6 per cent of pottery was dentate-stamped (Summerhayes 2001:53). The Kamgot (ERA) site is located upon an area of raised limestone on the western end of Babase in the Anir Group off New Ireland and is dated to 3300-3000 cal. BP (Summerhayes 2000b). At ERA, 8-11 per cent of the pottery assemblage has dentate stamping and four different vessel types were recorded: bowls 36 per cent, jars 36 per cent, globular pots 10 per cent and stands 12 per cent. Shown in Figure 2.5 are vessels from Forms I (open bowl/cup), VI (pot with everted rim, globular body) and VIII (vessel stands). The orifice diameters of the open bowls and pots varies from 20 to $36 \mathrm{~cm}$ and stand diameters from 15 to $30 \mathrm{~cm}$. The Tamuarawai site (EQS) is located on Emirau in the Mussau Islands and is dated to 3360-3160 cal. BP (Summerhayes et al. 2010). Six vessel forms were identified in the EQS assemblage, which is dominated by Forms I ( 25 per cent) and VI ( 49 per cent). Vessel Forms V and VIII are the second-most numerous at 10 per cent and 12 per cent, respectively. Finally, a small number (3 per cent) of vessels from Form IV (jar with horizontal rim, restricted neck) and VII (inward restricted upper vessel form) were recorded (Hogg 2011:60). Orifice diameters for 29 vessels (total 148) was 7-23 cm with most 11-14 cm (Hogg 2011, Appendix 3:149-152). 
(A)
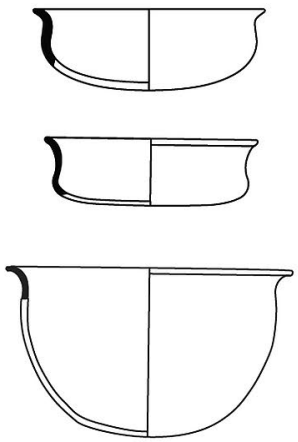

(B)

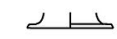

UNAI CHULU
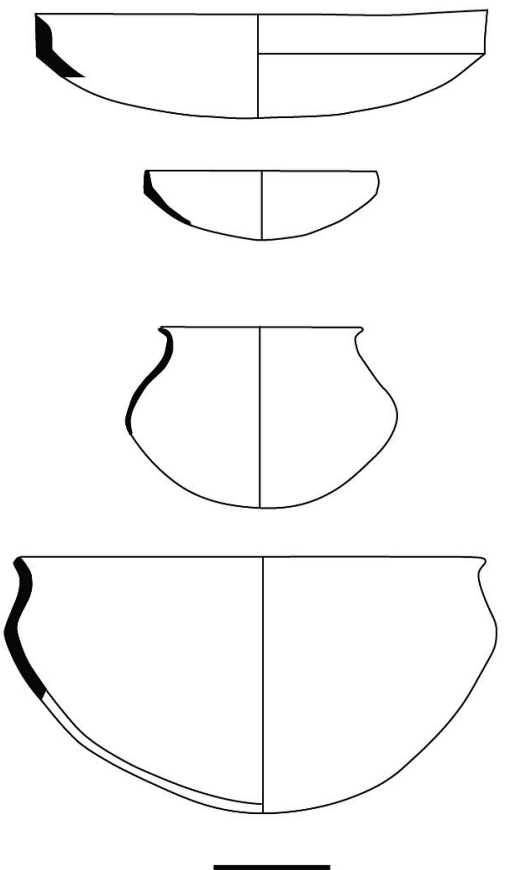

$10 \mathrm{~cm}$
UNAI BAPOT-1
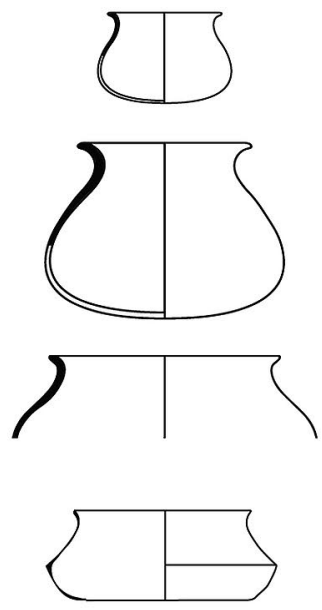

TARAGUE
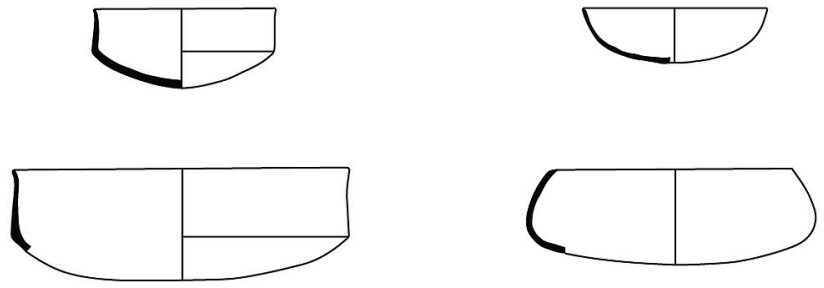

TAGA

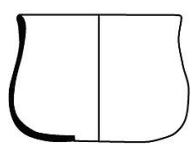

(not to scale)
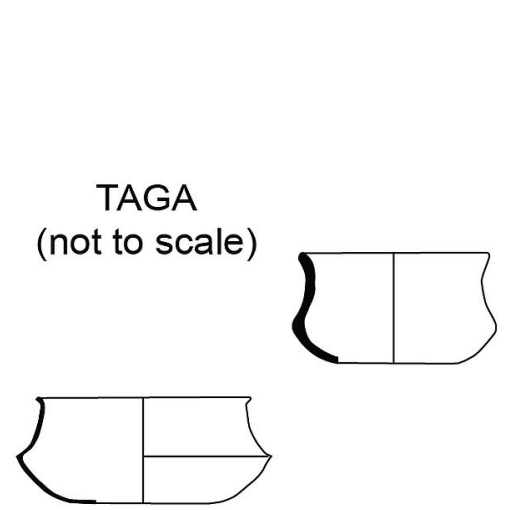

MANGILAO

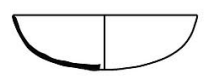

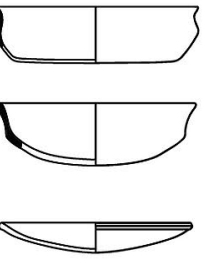

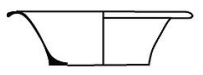

Figure 2.5. Reconstructed vessel forms from early Marianas sites.

Bapot-1 (A) vessels reconstructed by Winter (2015). Other vessel forms and rim profiles are from Bapot-1 (B) (Carson 2014), Unai Chulu (Haun et al. 1999), Tarague (Ray 1981), Mangilao (Dilli et al. 1998), Taga (Carson 2014).

Source: Authors' depiction, after Winter 2015, Carson 2014, Haun et al. 1999, Ray 1981, Dilli et al. 1998. 


\section{TALEPAKEMALAI (ECA)}
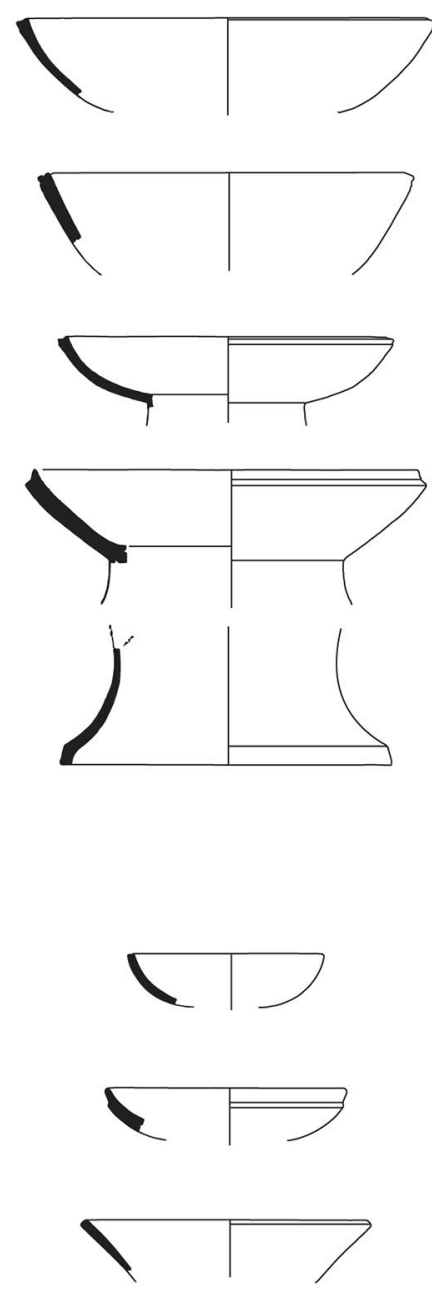

ARAWE
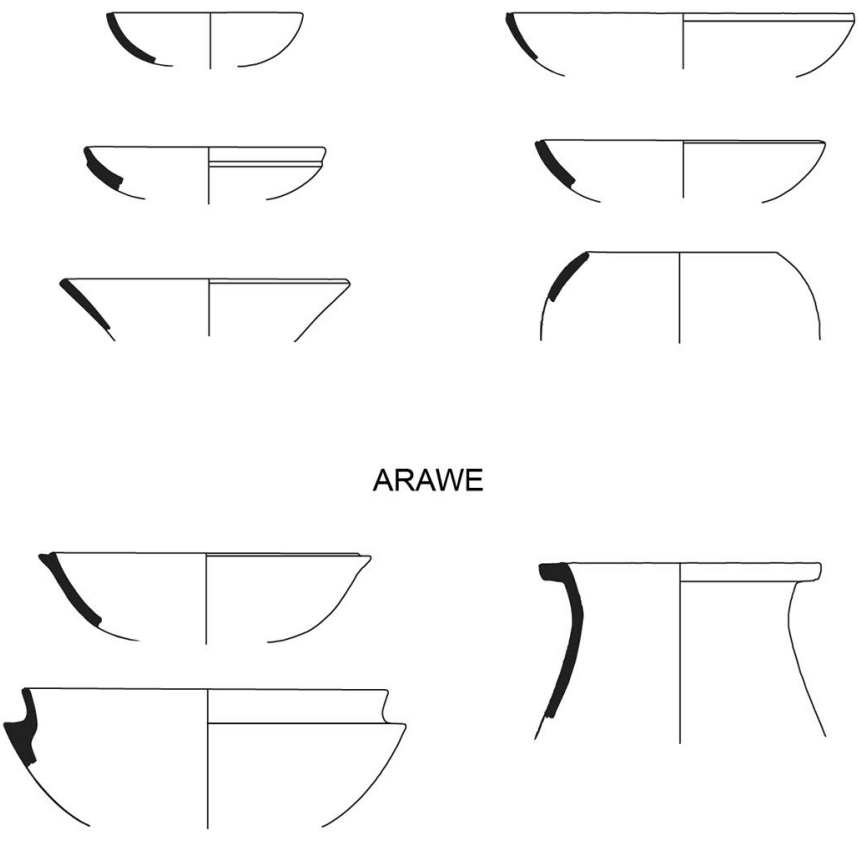

$\overline{10 \mathrm{~cm}}$
TAMUARAWAI (EQS)
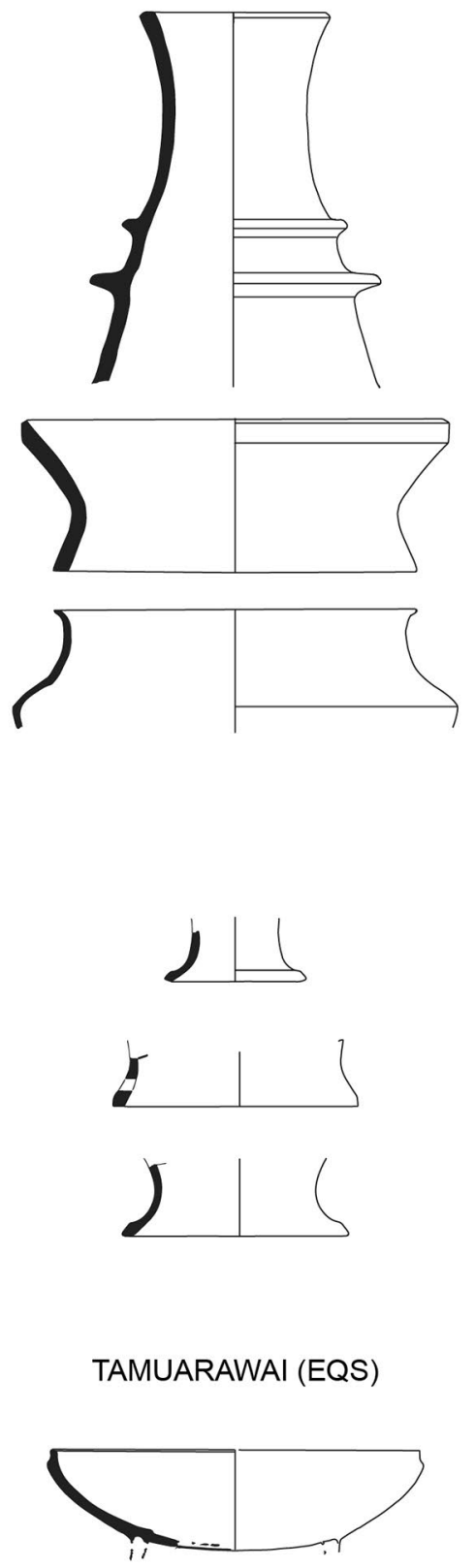

Figure 2.6. A selection of reconstructed vessels from Early Lapita sites in the Bismarck Archipelago. Illustrated vessels (decoration not shown) are from Talepakemalai (Kirch et al. 2015; Sand 2015), Kamgot and the Arawes (Summerhayes 2000a; Sand 2015), and Tamuarawai (Sand 2015).

Source: Authors' depiction, after Kirch et al. 2015, Sand 2015 and Summerhayes 2000a. 
There are significant differences between the early vessel forms in the Marianas and those in the Lapita assemblages surveyed (Figures 2.5 and 2.6). Only five of the 12 vessel forms reported from the Early Lapita site of Talepakemalai (ECA) occur in the Mariana Islands (bowl, dish, jar, pot, handle) with six of the eight generic vessel forms (I, II, III, IV, V, VI) identified by Summerhayes (2000a) present in the Mariana Islands. However, the apparent absence of Forms VII and especially VIII (ringfoot) is notable. The ringfoot is relatively common in the Neolithic of ISEA and occurs in the Northern Philippines at sites like Nagsabaran, as well as further south in Sulawesi (Azis et al. 2018; Hung 2008). The ringfoot is the most common vessel form in the Mussau ECA assemblage where it makes up almost 33 per cent of the vessel forms and has a frequency of 77 per cent at the EHB site, which may be the oldest Lapita site on Mussau (Kirch et al. 2015:58). Vessel stands/ringfeet are found in other Lapita assemblages including Kamgot (12 per cent), Tamuarawai (12 per cent) and Adwe (8 per cent). Except for two 'possible' stand sherds at Bapot-1 and Chalan Piao (mentioned above), there are no records of stands, ringfeet, or bowls/dishes on a ringfoot in the Marianas. In Lapita assemblages, small-to-large vessels were highly decorated with dentate stamping compared to the Marianas where Carson (2014:127) notes that only small vessels were marked with Achugao Incised decoration. In the Mariana Islands, vessels are generally smaller than those in the Talepakemalai site (orifice diameters $20-45 \mathrm{~cm}$ ) and at Adwe (orifice diameters 34-40 cm), but larger than the vessels reported from Tamuarawai (orifice diameters $7-23 \mathrm{~cm}$ with the majority falling between 11-14 cm). The Tamuarawai vessel sample was 19 per cent of the total and may not reflect the true range. The Kamgot vessels in Figure 2.5 have orifice diameters of $20-36 \mathrm{~cm}$, similar to Bapot-1 vessels (Winter 2015), but most are c. $25-36 \mathrm{~cm}$ in diameter.

\section{Discussion}

The timing and origins of the first ceramics brought to Pacific Islands by colonists is important for understanding Neolithic expansion for three reasons. First, while ISEA is an insular environment, the prehistoric maritime capacity during the dispersal phase is best understood from human arrival on remote Pacific Islands. Second, the timing of colonisation in Oceania in relation to movement through ISEA calibrates the overall Neolithic expansion rate. Third, ceramic attributes in Pacific Island assemblages can be compared with those from ISEA and other parts of Oceania to determine the migration pattern, and whether the spread of Neolithic material culture in different areas suggests horizontal (reticulate) or vertical (phylogenetic) transmission (Gray et al. 2010).

The comparison of Lapita Western Pacific and Marianas pottery presented here has focused on decoration, vessel form and tool type to determine whether a Marianas ceramic signal can be detected in Lapita pottery from the Bismarck Archipelago, as has been suggested by several researchers (e.g. Bellwood 2011; Carson 2014; Carson et al. 2013; Hung et al. 2011). Evidence for contact between the two groups would not only suggest that production of Lapita culture arose from the fusion of different Neolithic groups, but also that some of the people who colonised the Marianas-after making the longest open-ocean crossing in the world - then voyaged a further $1700 \mathrm{~km}$ to the Bismarck Archipelago, indicating a greater maritime dispersal capacity in the Neolithic than has generally been thought.

To investigate ceramic similarity, we made a design inventory for early Marianas pottery from published sources that suggests that no complex ceramic designs are shared between the Marianas and Western Pacific Lapita. The main parallels are in the use of a multi-toothed tool to mark pots and the similarity of some San Roque Incised designs that are comparable to several dentatestamped designs in Lapita assemblages. However, the great majority of Lapita designs are not 
shared with the Marianas and the toothed tool used to decorate some Achugao Incised vessels appears to be different from those used to mark Lapita pots. Vessel forms also differ between the Marianas and Western Pacific Lapita assemblages. As a result it is difficult to identify a movement from the Marianas that introduced 'some of the Lapita decorative repertoire into Oceania' (Bellwood 2011:S369).

From a ceramic design viewpoint, it is clear that the Early Lapita decorative system is strongly structured, with multiple rows/bands of designs applied to vessels along with complex designs that were widespread (e.g. designs such as the 'labyrinth', 'house', 'human face', 'mask', 'headdress' and 'bird'). Significant variation in the decoration of Lapita vessels suggests that design innovation was favoured, with new motifs and arrangements of motifs/designs the norm, and presumably reflecting social demand (see Chiu 2015). An alternative that the Lapita decorative system is highly variable due to design fragmentation during dispersal does not explain the generation of new designs/motifs at sites that were likely occupied for several centuries nor the persistence of several designs/motifs across large parts of the Lapita range.

One of the most important technological innovations that may have stimulated Lapita design growth was the development of a toolkit containing linear and curved dentate stamps that were probably simple to make and that allowed potters to create intricate and complicated designs that would be difficult to make with incision/plain stamps. There is no evidence for dentate-stamped arcs in Neolithic ceramics from the Northern Philippines, the Marianas nor in Sulawesi, and the tool appears to be an important Lapita invention (see Bedford and Sand 2007:3). We hypothesise that design innovation was favoured as it allowed Lapita artisans to maintain their position relative to the products of less-skilled potters, and the purpose of new designs was to appeal to a particular group or 'market', consistent with decorated pottery being used as a signalling device in social interactions. As new pottery designs represent an arbitrary change to the look of a commodity and have no functional value, it follows that selection of new designs allowed Lapita individuals/groups to separate themselves in some way. The creation and consumption of new designs during Early Lapita times, then, may have been a significant act that materialised the social position of the consumer and, to a lesser degree, the designer/pottery.

The decorative variation in Marianas pottery is modest with an intriguing divide between Achugao Incised and San Roque Incised designs, suggesting a functional difference in the use of decorated vessels. Although designs are arranged in rows/bands in the Marianas, there is less design variation and innovation relative to Lapita. This should not be taken to mean that early Marianas ceramics represent a 'stagnant' form of Neolithic pottery, as to construct the thinwalled, calcareous-tempered, red-slipped vessels of the Marianas clearly required significant artisanal ability (Winter 2015). However, the people who colonised the Marianas used ceramics in a different way and the remote location was very different to the Bismarck Archipelago, which had a social and geographic setting conducive to high levels of interaction and design variation during the dispersal of Lapita culture.

The generalised vessel forms of the two assemblages overlap, but there are significant differences between Lapita vessels and those of the Marianas. These include the use of dentate stamping to decorate large and small vessels in Lapita assemblages, contrasted with the restriction of Achugao Incised decoration to small vessels (Carson 2014:127), the noteworthy absence of the ringfoot/ stand in the Marianas compared to other parts of ISEA and the Bismarck Archipelago, and the greater size and diversity of vessel forms in Lapita assemblages compared with the Marianas. 


\section{Conclusion}

The oldest ceramic assemblages found on previously uninhabited Pacific Islands provide a pristine record of Neolithic dispersals. Decorated pottery in the Marianas was initially seen as similar only in a generic sense to Lapita pottery (Bellwood 1978:282; Craib 1999:482), and Butler specifically ruled out a close connection:

It is now clear that the early Marianas ceramics are not related to Lapita ceramics although both derive ultimately out of the same general milieu of late Neolithic cultures in Island southeast Asia (1995:202).

The possibility that a migration from the Marianas reached the Bismarck Archipelago has been developed from the excavation of new ceramic assemblages from the Northern Philippines and the Marianas on the one hand, and an apparent absence of early decorated ceramics in parts of Indonesia on the other.

The apparent lack of pottery marked with punctate- and circle-stamping in central-eastern Indonesia and the presence of Kutau-Bao (New Britain) obsidian in Borneo indicated a strand of Neolithic migration that passed through the Celebes Sea into the Pacific. One group colonised the Marianas while another reached the Bismarck Archipelago where it was then joined by a dispersal from the Marianas. Undermining this hypothesis is, first, the recent discovery of sites in Sulawesi with dentate-stamped and lime-impressed pottery, which indicates that people who decorated pottery with stamped circles and toothed tools were also in Indonesia. Second, the putative connection between the Marianas and Western Pacific Lapita is based on the visual similarity of a small number of sherds with potentially similar designs (e.g. Carson et al. 2013: Figure 7). Measuring historical relationships using positive design matches ignores the degree of assemblage dissimilarity and will tend to favour hyper-migrationist models of Neolithic dispersal. The chronology of dentate-/punctate- and circle-stamping in ISEA is also poorly resolved, and the comparison of ceramic assemblages of different ages will further lead to inaccurate historical reconstructions of Neolithic expansion.

Ceramic comparisons are especially problematic when a small set of designs from an assemblage/ location is compared with those in a rich design repertoire such as Lapita pottery. Some designs are likely to be similar due to chance while others could be retained from ancestral traditions. Shared ceramic traits/techniques such as red slip, lime infilling, circle- and dentate-/punctatestamping, for example, are widespread attributes of Neolithic and Iron Age ceramics in ISEA - Western Pacific, and do not of themselves provide evidence for a migration from the Marianas to the Bismarcks, nor that the Marianas was colonised from the Northern Philippines. Pottery designs, vessel forms and a multi-toothed tool used in the Marianas are significantly different from those in Lapita assemblages, indicating distinct dispersals and the spread of a culturally diverse Neolithic in ISEA and the Western Pacific.

\section{Acknowledgements}

We thank Michelle Langley and Mirani Litster for assistance with photography, Stuart Bedford for discussing Lapita ceramics and Wallace Ambrose for supplying sherds for the tool mark comparison. We also thank N. Stjärna for technical support in producing the vessel form figures. All figures were produced by the authors. 


\section{References}

Anson, D. 1983. Lapita pottery of the Bismarck Archipelago and its affinities. Unpublished PhD thesis, University of Sydney, Sydney.

Azis, N., C. Reepmeyer, G. Clark, Sriwigati and D.A. Tanudirjo 2018. Mansiri in North Sulawesi: A new dentate-stamped pottery site in Island Southeast Asia. In S. O'Connor, D. Bulbeck and J. Meyer (eds), The archaeology of Sulawesi: Current research on the Pleistocene to the Historic period, pp. 191-205. Terra Australis 48. ANU Press, Canberra. doi.org/10.22459/TA48.11.2018.

Bedford, S. and C. Sand 2007. Lapita and Western Pacific settlement: Progress, prospects and persistent problems. In S. Bedford, C. Sand and S.P. Connaughton (eds), Oceanic explorations: Lapita and Western Pacific settlement, pp. 1-16, Terra Australis 26. ANU E Press, Canberra. doi.org/10.22459/ TA26.2007.

Bedford, S., M. Spriggs, H. Buckley, F. Valentin, R. Regenvanu and M. Abong 2010. A cemetery of first settlement: The site of Teouma, south Efate, Vanuatu. In C. Sand and S. Bedford (eds), Lapita: Ancêtres Océaniens/Oceanic ancestors, pp. 140-161. Musée du quai Branly and Somogy, Paris.

Bellwood, P. 1978. Man's conquest of the Pacific. Collins, Auckland, Sydney and London.

Bellwood, P. 2005. First farmers: The origins of agricultural societies. Blackwell, Oxford.

Bellwood, P. 2011. Holocene population history in the Pacific region as a model for worldwide food producer dispersals. Current Anthropology 52(4):S363-S378. doi.org/10.1086/658181.

Bellwood, P. and P. Koon 1989. 'Lapita colonists leave boats unburned!' The question of Lapita links with Island Southeast Asia. Antiquity 63(240):613-622. doi.org/10.1017/S0003598X00076572.

Birks, L. 1973. Archaeological excavations at Sigatoka Dune Site, Fiji. Bulletin of the Fiji Museum No. 1. Fiji Museum, Suva.

Buckley, C.D. 2012. Investigating cultural evolution using phylogenetic analysis: The origins and descent of the Southeast Asian tradition of warp ikat weaving. PLoS ONE 7(12): e52064. doi.org/10.1371/ journal.pone.0052064.

Butler, B.M. 1994. Early prehistoric settlement in the Marianas Islands: New evidence from Saipan. Man and Culture in Oceania 10:15-38.

Butler, B.M. 1995. Archaeological investigations in the Achugao and Matansa areas of Saipan, Mariana Islands. Micronesian Archaeological Survey Report No. 30. Department of Community and Cultural Affairs, Saipan.

Carson, M. 2008. Refining earliest settlement in Remote Oceania: Renewed archaeological investigations at Unai Bapot, Saipan. Journal of Island and Coastal Archaeology 3(1):115-139. doi.org/10.1080/155 64890801909722 .

Carson, M.T. 2014. First settlement of Remote Oceania: Earliest sites in the Mariana Islands. Springer, Heidelberg. doi.org/10.1007/978-3-319-01047-2.

Carson, M.T. and D. Welch 2005. Archaeological survey, mapping, and testing of Bapot Latte Site (SP-1-0013) in Laulau, Saipan, Commonwealth of the Northern Mariana Islands. Report prepared for the Commonwealth of the Northern Mariana Islands Division of Historic Preservation, Saipan. Unpublished. International Archaeological Research Institute, Honolulu.

Carson, M.T., H.-C. Hung, G.R. Summerhayes and P. Bellwood 2013. The pottery trail from Southeast Asia to Remote Oceania. The Journal of Island and Coastal Archaeology 8(1):17-36. doi.org/10.1080/ 15564894.2012.726941. 
Chiu, S. 2015. Where do we go from here? Social relatedness reflected by motif analysis. In C. Sand, S. Chiu and N. Hogg (eds), The Lapita Cultural Complex in time and space: Expansion routes, chronologies and typologies, pp. 185-206. Archeologia Pasifika 4. Institut d'archéologie de la NouvelleCalédonie et du Pacifique (IANCP), Nouméa.

Clark, G. 2004. Radiocarbon dates for the Ulong site in Palau and implications for western Micronesian prehistory. Archaeology in Oceania 39: 26-33. doi.org/10.1002/j.1834-4453.2004.tb00554.x.

Craib, J. 1990. Archaeological investigations at Mochong, Rota, Mariana Islands. Unpublished report prepared for Historic Preservation Division, Commonwealth of the Northern Mariana Islands.

Craib, J. 1999. Colonisation of the Marianas Islands: New evidence and implications for human movements in the Western Pacific. In J.-C. Galipaud and I. Lilley (eds), The Pacific from 5000 to 2000 BP. Colonization and Transformations, pp. 477-485. IRD Éditions, Paris.

Denham, T., C. Bronk Ramsey and J. Specht 2012. Dating the appearance of Lapita pottery in the Bismarck Archipelago and its dispersal to Remote Oceania. Archaeology in Oceania 47(1):39-46. doi.org/10.1002/j.1834-4453.2012.tb00113.x.

Dilli, B.J., A.E. Haun and S.T. Goodfellow 1998. Archaeological mitigation program Mangilao Golf Course project area, Mangilao Municipality, Territory of Guam. Volume II: Data analyses. Unpublished. PHRI, Hawai i

Fitzpatrick, S.M. and R.T. Callaghan 2013. Estimating trajectories of colonisation to the Mariana Islands, Western Pacific. Antiquity 87(337):840-853. doi.org/10.1017/S0003598X00049504.

Gifford, E.W. 1951. Archaeological excavations in Fiji. University of California Anthropological Records 13:189-288. University of California Press, Berkeley and Los Angeles.

Golson, J. 1972. Both sides of the Wallace Line: New Guinea, Australia, Island Melanesia and Asian prehistory. In N. Barnard (ed.), Early Chinese art and its possible influence in the Pacific Basin, pp. 533-595. Intercultural Arts Press, New York.

Gray, R.D., D. Bryant and S.J. Greenhill 2010. On the shape and fabric of human history. Philosophical Transactions: Biological Sciences 365(1559):3923-3933. doi.org/10.1098/rstb.2010.0162.

Haun, A.E., J.A. Jimenez and M. Kirkendall 1999. Archaeological investigations at Unai Chulu, Island of Tinian, Commonwealth of the Northern Mariana Islands. Unpublished report prepared for Department of the Navy, Naval Facilities Engineering Command, Hilo.

Hedrick, J.D. n.d. Archaeological investigation of Malo prehistory: Lapita settlement strategy in the northern New Hebrides. Unpublished draft PhD thesis, University of Pennsylvania, Philadelphia, PA.

Hogg, N. 2011. Specialised production of Early Lapita pottery: A skill analysis of pottery from the Island of Emirau. Unpublished MA thesis, The University of Otago, Dunedin.

Hung, H.-C. 2008. Migration and cultural interaction in Southern Coastal China, Taiwan and the Northern Philippines, 3000 BC to AD 100: The early history of the Austronesian-speaking populations. Unpublished $\mathrm{PhD}$ thesis, The Australian National University, Canberra.

Hung, H.-C., M.T. Carson, P. Bellwood, F.Z. Campos, P.J. Piper, E. Dizon, M.J.L.A. Bolunia, M. Oxenham and Z. Chi 2011. The first settlement of Remote Oceania: The Philippines to the Marianas. Antiquity 85:909-926. doi.org/10.1017/S0003598X00068393.

Hunter-Anderson, R.L. and B.M. Butler 1995. An overview of Northern Marianas prehistory. Micronesian Archaeological Survey Report Number 31. The Micronesian Archaeological Survey, Division of Historic Preservation, Department of Community and Cultural Affairs, Saipan. 
Kirch, P.V., S. Chiu and Y-Y. Su 2015. Lapita ceramic vessel forms of the Talepakemalai site, Mussau Islands, Papua New Guinea. In C. Sand, S. Chiu and N. Hogg (eds), The Lapita Cultural Complex in time and space: Expansion routes, chronologies and typologies, pp. 49-61. Archeologia Pasifica 4. IANCP, Nouméa.

MacLachlan, R.R.C. 1938. Native pottery from central and southern Melanesia and western Polynesia. Journal of the Polynesian Society 186:64-89.

Marck, J. 1977. Interim report of the 1977 Laulau excavations, Saipan, CNMI. Unpublished manuscript on file at Division of Historic Preservation, Department of Community and Cultural Affairs, Commonwealth of the Northern Marianas.

Moore, D.R. 1983. Measuring change in Marianas pottery: The sequence of pottery production at Tarague, Guam. Unpublished MA thesis, The University of Guam, Mangilao.

Moore, D.R. and R.L. Hunter-Anderson 1999. Pots and pans in the intermediate Pre-Latte (25001600 bp) Marianas Islands, Micronesia. In J.-C. Galipaud and I. Lilley (eds), The Pacific from 5000 to 2000 BP. Colonization and transformations, pp. 487-503. IRD Éditions, Paris.

Moore, D.R., R.L. Hunter-Anderson, J.R. Amesbury and E.F. Wells 1992. Archaeology at Chalan Piao, Saipan. Report to the Historic Preservation Division, Department of Community and Cultural affairs, Commonwealth of the Northern Mariana Islands. Unpublished. Micronesian Archaeological Research Services, Guam.

Noury, A. and J.-C. Galipaud 2011. Les Lapita: Nomades du Pacifique. IRD Éditions, Marseille. doi.org/10.4000/books.irdeditions.653.

Pellett, M. and A. Spoehr 1961. Marianas archaeology: Report on the excavation on Tinian. Journal of the Polynesian Society 70(3):321-325.

Petchey, F., G. Clark, O. Winter, P. O’Day and M. Litster 2017. Colonisation of Remote Oceania: New dates for the Bapot-1 site in the Marianas. Archaeology in Oceania 52(2): 108-126. doi.org/10.1002/ $\operatorname{arco.5108.}$

Rainbird, P. 2004. The archaeology of Micronesia. Cambridge University Press, Cambridge. doi.org/ 10.1017/CBO9780511616952.

Ray, E.R. 1981. The material culture of prehistoric Tarague Beach, Guam. Unpublished MA thesis, Arizona State University.

Ray, E., W.R. Fortini and J.L. Babauta 1996. Archaeological data recovery at Akitsu Shoji’s residence in San Roque, Saipan, CNMI. Unpublished report prepared for AB Business Management and Consulting Services, Saipan.

Reepmeyer, R., M. Spriggs, Anggraeni, P. Lape, L. Neri, W.P. Ronquillo, T. Simanjuntak, G. Summerhayes, D. Tanudirjo and A. Tiauzon 2011. Obsidian sources and distribution systems in Island Southeast Asia: New results and implications from geochemical research using LA-ICPMS. Journal of Archaeological Science 38(11): 2995-3005. doi.org/10.1016/j.jas.2011.06.023.

Rice, P.M. 1987. Pottery analysis. A sourcebook. The University of Chicago Press, Chicago and London.

Sand, C. 2010. Lapita Calédonien: Archéologie d'un premier peuplement Insulaire Océanien. Collection Travaux et Documents Océanistes 2. Société des Océanistes, Paris. doi.org/10.4000/books.sdo.1128.

Sand, C. 2015. Comparing Lapita pottery forms in the Southwestern Pacific: A case study. In C. Sand, S. Chiu and N. Hogg (eds), The Lapita Cultural Complex in time and space: Expansion routes, chronologies and typologies, pp. 125-171. Archeologia Pasifika 4. IANCP, Nouméa. 
Sheppard, P.J., S. Chiu and R. Walter 2015. Re-dating Lapita movement into Remote Oceania. Journal of Pacific Archaeology 6(1):26-36.

Solheim, W.G. II. 1952. Oceanian pottery manufacture. Journal of East Asiatic Studies 1(2):1-40.

Solheim, W.G. II. 1959. Further notes on the Kalanay pottery complex in the P.I. Asian Perspectives 3:157-172.

Solheim, W.G. II. 1964a. Pottery and the Malayo-Polynesians. Current Anthropology 5(5): 360-386. doi.org/10.1086/200526.

Solheim, W.G. II. 1964b. Further relationships of the Sa-Huynh-Kalanay pottery tradition. Asian Perspectives 8:196-211.

Solheim, W.G. II. 2000. Taiwan, coastal South China and northern Vietnam and the Nusantao maritime trading network. Journal of East Asian Archaeology 2(1-2):273-284. doi. org/10.1163/156852300509727.

Spoehr, A. 1957. Marianas prehistory: Archaeological survey and excavations on Saipan, Tinian and Rota. Fieldiana Anthropology 48. Chicago Natural History Museum, Chicago. doi.org/10.5962/bhl. title.3552.

Summerhayes, G.R. 2000a. Lapita interaction. Terra Australis 15. Department of Archaeology and Natural History and the Centre for Archaeological Research, The Australian National University, Canberra.

Summerhayes, G.R. 2000b. Far Western, Western, and Eastern Lapita: A re-evaluation. Asian Perspectives 39(1-2):109-138. doi.org/10.1353/asi.2000.0013.

Summerhayes, G.R. 2001. Lapita in the far west: Recent developments. Archaeology in Oceania 36(2):53-63. doi.org/10.1002/j.1834-4453.2001.tb00478.x.

Summerhayes, G.R., E. Matisoo-Smith, H. Mandui, J. Allen, J. Specht, N. Hogg and S. McPherson 2010. Tamuarawai (EQS): An early Lapita site on Emirau, New Ireland, PNG. Journal of Pacific Archaeology 1(1):62-75.

Winter, O. 2015. Colonisation of the Marianas Islands: Affinities and differences between ISEA and Pacific cultures in the 1st millennium BC. Unpublished PhD thesis, The Australian National University, Canberra.

Winter, O., G. Clark, A. Anderson and A. Lindahl 2012. Austronesian sailing to the northern Marianas, a comment on Hung et al. (2011). Antiquity 86(333):898-910. doi.org/10.1017/ S0003598X00047992.

\section{Appendix 2.1. Marianas decorated sherds (not to scale)}

\begin{tabular}{|l|l|l|}
\hline Site/Island & Number & Reference \\
\hline Achugao, Saipan & $\begin{array}{l}9,11,13,14,17,18,20,22,24,25,26,27, \\
28,30,33,35,36,37,38,42,53,54\end{array}$ & Butler 1995; Hung et al. 2011 \\
\hline Bapot-1, Saipan & $1,31,34,51,52,63$ & Carson 2008; Winter 2015 \\
\hline Mangilao, Guam & 5,16 & Dilli et al. 1998 \\
\hline San Roque, Saipan & $39,45,48,49,69$ & Ray et al. 1996 \\
\hline Taga, Tinian & $\begin{array}{l}3,4,7,8,10,12,15,19,21,23,29,32,40, \\
41,46,55,64,65,66,67,68,70,71,72\end{array}$ & $\begin{array}{l}\text { Carson 2014; Carson et al. 2013; Hung et al. 2011; } \\
\text { Pellett and Spoehr 1961 }\end{array}$ \\
\hline Unai Chulu, Tinian & $2,6,43,44,47,50,56,57,58,59,60,61,62$ & Haun et al. 1999 \\
\hline
\end{tabular}




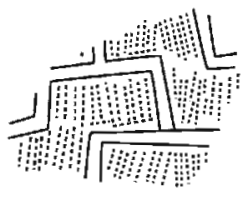

1

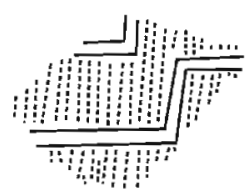

2

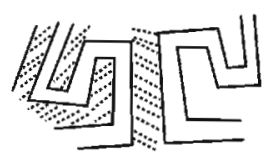

3

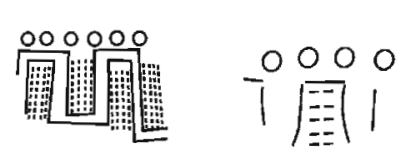

4

5
00080080000000000

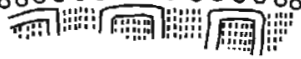

6

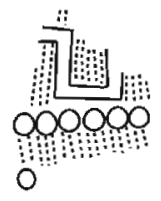

11

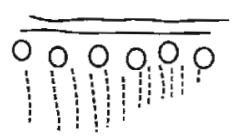

16

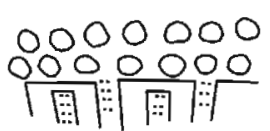

7

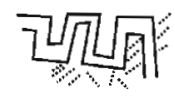

12

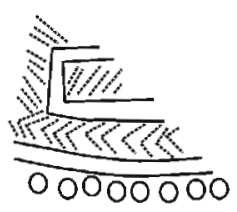

17
$\frac{\nVdash}{0}$

8

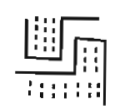

13

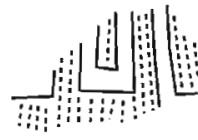

9

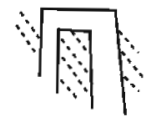

14

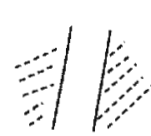

10

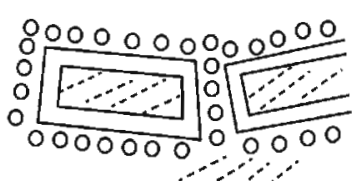

18

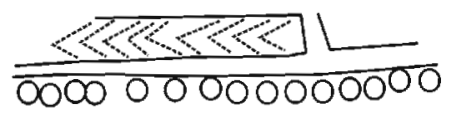

20<smiles>C1CCCCCCCCCCC1</smiles>

24

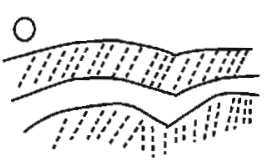

29

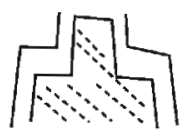

25

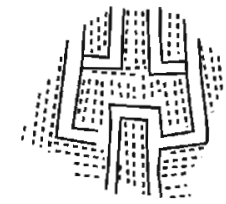

30

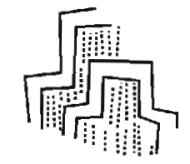

21

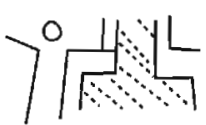

26<smiles>Cc1ccccc1OOO</smiles>

31

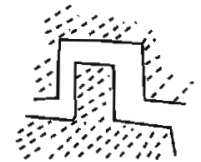

22<smiles>c1ccccc1</smiles>

27

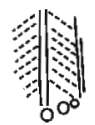

23

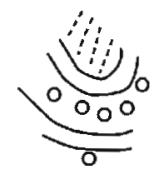

28
ए।

9 


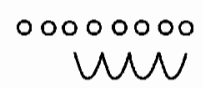

34

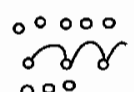

39

$\overbrace{}^{\circ}$

44

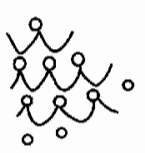

49

MOONO NM

55

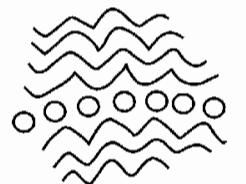

60

o.

64

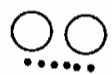

69
$\Omega$

35

$\circ 000$
0000
000

40

分卤

45

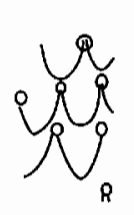

50

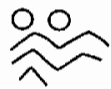

56 $\therefore: 8$

36

var
qRe

41

RN

Rqa

46

m

51

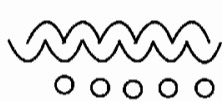

52

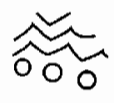

57
280

37

No9

42

U9R

47<smiles>c1cc2ccc1o2</smiles>

53

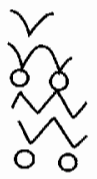

58

(ㅇ) (ㅇ) () ()

66

67<smiles>[Z]C(C)=[V]</smiles>

54<smiles>O=C(O)C(=O)Oc1ccccc1OCCO</smiles>

59
38

คำ

43

थिरिด

48
00000 0080000<smiles>C=CC(=O)OOC1CO1</smiles>

62

\section{1}

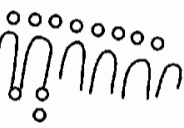

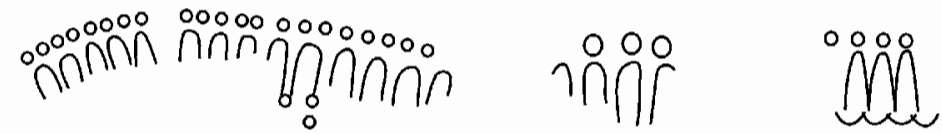

63 ॠ०0000\%

65

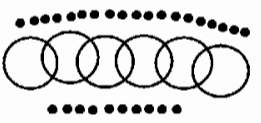

70

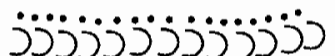<smiles>C1[C@@H]2O[C@@H]1[C@H]1O[C@@H]2O1</smiles>

71

72 


\section{Appendix 2.2. Marianas pottery designs identified in the literature and reconstructed from incomplete designs}

$1 \mathrm{~m}^{2}$

2

mon

3 MNivinin

- rarararar

5 rimiririarik

6

inimiairiag - vivivinikiki

iriagiaiking yikiniminimi

7 riciariaria

00000000000000000000000

- riariariag

0000000000000000000000000 ㅇaiaia

9 0000000000000000000000000

\section{0}

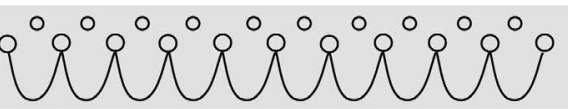

11

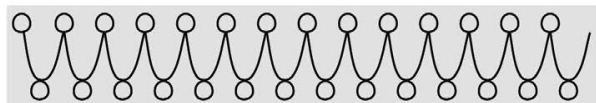

12 Winto

$\cap \cap \cap \cap \cap \cap \cap \cap \cap \cap \cap \cap n$

13 iriagiaisigia

14 O 00000000000000000000000
15

RRRRRRRRRRRRR

0000000000000000000

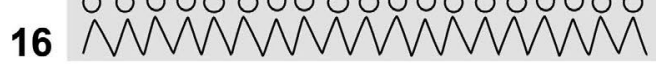

OOOOOOOOOOOOOOOOOOO (1)

17

กำำ

19

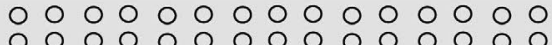

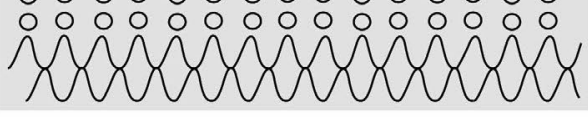

20

$\mathrm{NONO}^{\circ}$

21

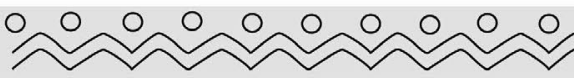

22

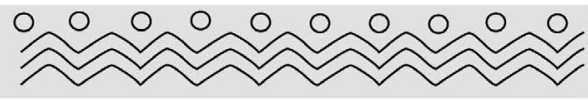

23

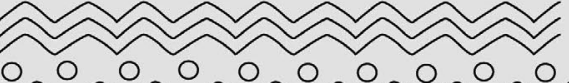

000000000000000000000000

24

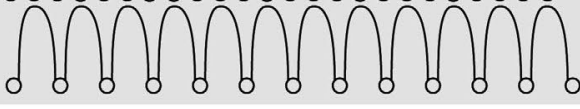

25

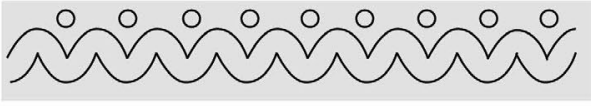

26

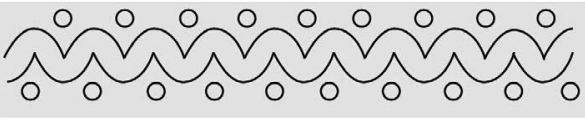

27

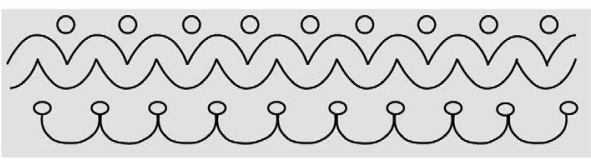


28

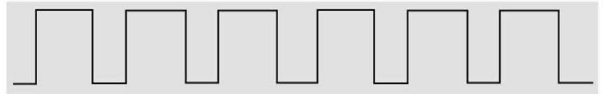

29 $\square \sqrt{\square} \square \sqrt{\square} \square$

30

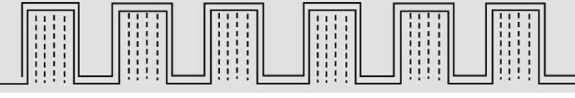

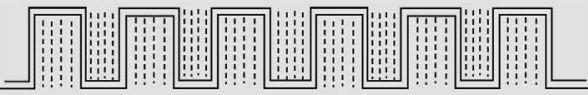

31 000000000000000000000000

32 浯: 0000000000000000000000000
00000000000000000000000

33

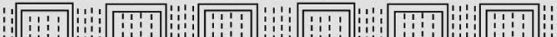

33 90000000000000000000000000000000 000000000000000000000000000000000

34 0000000000000000000000000

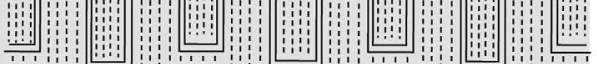

35

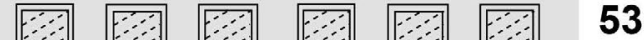

36

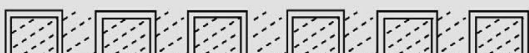

37

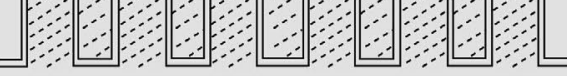

$38 \because \cdots \cdots$

$39 \quad \because \cdots \cdots$ 0000000000000000000000000000000000 [0 $\because \cdots \cdots$

40000000000000000000000000000000000

000000000000000000000000000000000 우 $\because \cdots \cdots$ 000000000000000000000000000000000

41

$\therefore \cdots \cdots$

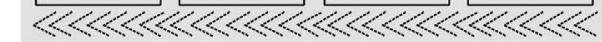

$42 \overline{0000000000000000000000000000000}$

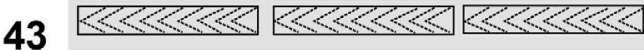

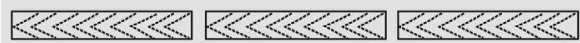

$44 \overline{0000000000000000000000000000000}$

45

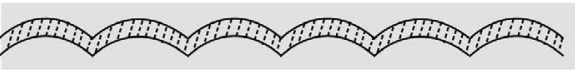

46

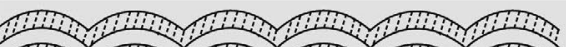

47

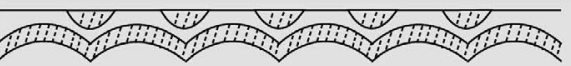

480000000000000000000000000

$49 \overline{0000000000000000000000000}$

50 ooooooo

0000000000000000000000000

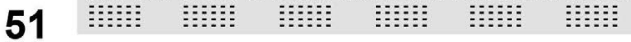

52

$0,0,0,0,0,0,0,0,0,0,0,0,0,0.0,0,0,0,0,0,0,00$

000000000000000000000000

$\begin{array}{lllllllllllll}0 & 0 & 0 & 0 & 0 & 0 & 0 & 0 & 0 & 0 & 0 & 0 & 0\end{array}$

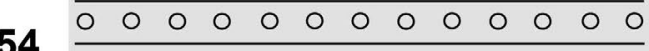

$\overline{0000000000000000000000000}$

$55 \overline{0000000000000000000000000}$

0000000000000000000000000 $\because \cdots \cdots \cdots$

5600000000000000000000000000

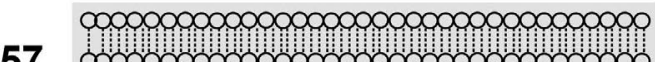

58

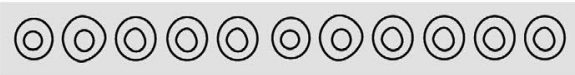



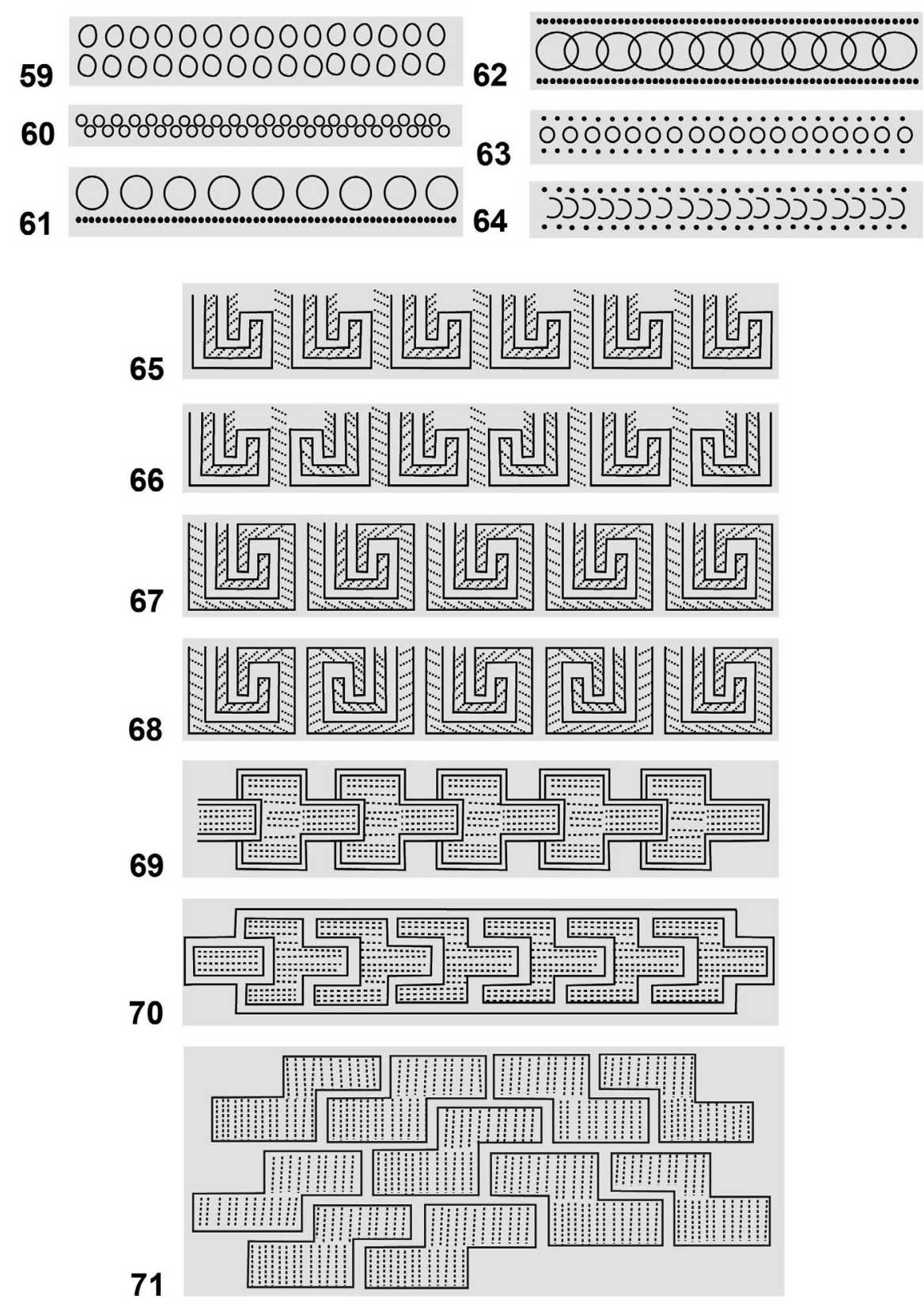

72
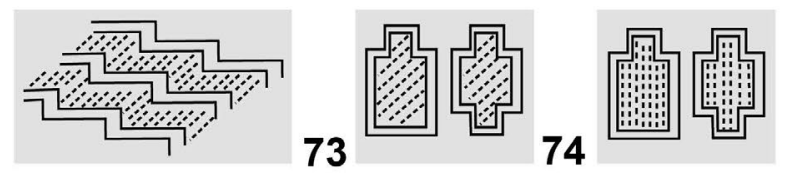
This text is taken from Debating Lapita: Distribution, Chronology, Society and Subsistence, edited by Stuart Bedford and Matthew Spriggs, published 2019 by ANU Press,

The Australian National University, Canberra, Australia.

doi.org/10.22459/TA52.2019.02 